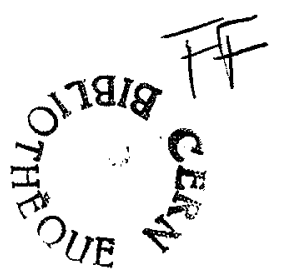

EUROPEAN ORGANIZATION FOR NUCLEAR RESEARCH
CER-TIS-RP 89 . T

9

CERN/TIS-RP/89-17

16 November 1989

\title{
MONITORING OF ACCELERATOR-PRODUCED RADIONUCLIDES IN AIR USING THERMOLUMINESCENCE DETECTORS
}

\author{
J.W.N. Tuyn and M. Féron
}

CERN, 1211 Geneva 23, Switzerland

\begin{abstract}
Inside the CERN high-energy proton accelerators a mixture of mainly short-lived radionuclides is produced during operation. The principal radionuclides are ${ }^{11} \mathrm{C},{ }^{13} \mathrm{~N},{ }^{15} \mathrm{O}$ and ${ }^{41} \mathrm{Ar}$. LiF TL detectors (TLD-700) have been used successfully for many years at CERN for air monitoring. The present paper reports on experimental work with LiF TL detectors exposed inside a cylindrical air volume (diameter $46 \mathrm{~cm}$ ) of variable height. The TL response versus height of the air column was established for a radioactive gas mixture taken from the $600 \mathrm{MeV}$ Synchrocyclotron. For an air column with a height of $30 \mathrm{~cm}$, typically a calibration value in ${ }^{137} \mathrm{Cs}$, a dose equivalent of 9.0 pSv per Bq. $\mathrm{m}^{-3} \cdot \mathrm{h}$ was found. During these experiments it was found that the response of bare uncovered LiF detectors was influenced by the presence of ozone in the air. Ozone-induced TL peaks appear at $\sim 110^{\circ} \mathrm{C}$ and $340^{\circ} \mathrm{C}$. Typical TL response values found after exposures of 0.5 hour in air containing $2 \mathrm{ppm}$ of ozone were equivalent to a dose of up to $0.09 \mathrm{mSv}$ of ${ }^{137} \mathrm{Cs}$.
\end{abstract}
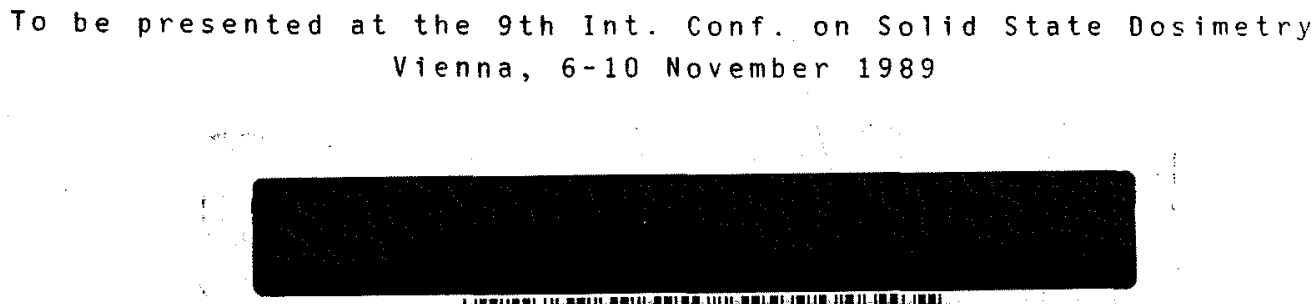

P00030827 


\section{INTRODUCTION}

At CERN, The European Laboratory for Elementary Particle Physics, a mixture of mainly short-lived radionuclides is produced during operation of the high-energy accelerators in the primary proton-beam areas. Continuous monitoring of these radionuclides is routinely carried out with either pairs of GM counters or differential ionization chambers. A simple method to estimate the total annual activity released was introduced some years ago at the $600 \mathrm{MeV}$ synchrocyclotron (SC) using ${ }^{7}$ LiF TL detectors ${ }^{1}$ ). The arrival of an automatic Alnor TL reader made it necessary to recalibrate the dose rate versus activity relationship as a function of air volume. Moreover, the effect of ozone (always present in accelerator beam areas) on the TL read-out was studied in detail. The TLD measurements will be compared with another point-like detector: a so-called silicon PIN photodiode.

\section{EXPERIMENTAL ARRANGEMENTS}

Air in primary proton-beam areas is activated mainly by spallation reactions, either caused by the primary beam passing through air or secondary particles. The principal radionuclides produced in this way are short-lived positron emitters 1 ike ${ }^{10} \mathrm{C},{ }^{11} \mathrm{C},{ }^{13} \mathrm{~N},{ }^{14} \mathrm{O}$ and ${ }^{15} \mathrm{O}$. In addition comes the production of ${ }^{41} \mathrm{Ar}$ by low-energy secondary neutrons. The composition of the radionuclide mixture in the stacks of the $600 \mathrm{MeV} \mathrm{SC}$ was determined previously ${ }^{2}$ ) and found to contain up to $51 \%$ of ${ }^{11} \mathrm{C}$, with ${ }^{13} \mathrm{~N}$ and ${ }^{15} \mathrm{O}$ contributing together about $47 \%$. During this present experiment air was taken out of the so-called ISOLDE target area of the SC and pumped into a cylindrical perspex volume of 100 I with a diameter of $46 \mathrm{~cm}$ and containing a piston to vary the height of the active air column above the detectors positioned in the centre of the bottom plate. The TL detectors used were Harshaw ${ }^{7}$ LiF (TLD-700) chips placed inside an Alnor slide-holder badge combination. The difference in read-out value between the detectors behind the open window covered with $7 \mathrm{mg} / \mathrm{cm}^{2}$ of plastic and those in positions shielded with $300 \mathrm{mg} / \mathrm{cm}^{2}$ was related to the integrated exposure to the air activity. The air activity was measured using an ionization chamber type Johnston Triton 955 B.

This monitor pumped the radioactive air out of the exposure cylindre at a speed of $101 / \mathrm{min}$, which implies 6 air renewals per hour in the exposure volume. 
This air monitor was carefully calibrated for acceleratorproduced radionuclides in the past ${ }^{3}$ ). The TLD's were evaluated with the Alnor hot-nitrogen reader using a read-out cycle composed of a $1 \mathrm{~h}$ pre-read anneal at $80^{\circ} \mathrm{C}$, followed by a read-out of $10 \mathrm{~s}$ at $340^{\circ} \mathrm{C}$, an annealing of $10 \mathrm{~s}$ at $380^{\circ} \mathrm{C}$ followed finally by a second read-out at $340^{\circ} \mathrm{C}$ to check the background.

In addition to the TL measurements another point-like detector was used: a silicon PIN photodiode siemens type BPW-34 used in the pulse mode. Such detectors have a sensitive area of $2.75 \times 2.75 \mathrm{~mm}$ covered (unfortunately) by a $0.4 \mathrm{~mm}$ thick plastic layer which decreases its potential beta. sensitivity. Those detectors are very low in price and therefore gradually replacing conventional GM counters ${ }^{4}$ for many applications.

Finally, the TL detectors were also exposed to air containing ozone of different concentrations up to $11 \mathrm{ppm}$ in a conventional glove box. The ozone concentration was determined using a Dasibi model 1003-AH monitor. Ozone exposures were carried out, since it is always present in irradiated air together with $\mathrm{NO}_{x}$, and the initial $\mathrm{TL}$ measurements without protective foil indicated a possible effect. The effect of the ozone exposure was measured without using the pre-read anneal at $80^{\circ} \mathrm{C}$.

\section{EXPERTMENTAL RESULTS AND DISCUSSION}

The net dose measured with the ${ }^{7} \mathrm{LiF}$ TL behind the open window after subtraction of the dose measured with the ${ }^{7} \mathrm{LiF}$ behind 300 $\mathrm{mg} \cdot \mathrm{cm}^{-2}$, using ${ }^{137} \mathrm{Cs}$ calibration related to the height of the air column and normalized per $B q \cdot m^{-3} \cdot h$, is presented in Fig. 1. The maximum dose value, already reached for a height of $\sim 40 \mathrm{~cm}$, was 9.5 pSv. Bq ${ }^{-1} \cdot \mathrm{m}^{3} \cdot \mathrm{h}^{-1}$. This value is lower than what was found previously ${ }^{1}$ ) due to the less favourable geometry of the Alnor slide and badge holder for beta dosimetry of large volume sources. The holes in the holders limit in fact the detected electrons and positrons to a cone with a top angle of about $40^{\circ} \mathrm{C}$. In Fig. 1 is also given the count rate versus height measured with the silicon PIN photodiode. As expected from the difference in measurement geometry for the two types of detectors, as well as the difference in measured quantity (dose versus counts), the shape of the two curves is slightly different. Also the $\beta / \gamma$ ratio measured for the ${ }^{7} \mathrm{LiF}$ TL detector and the PIN diode are different due to the difference in absorber layer in front of them (10.5 and 6.9, respectively, at $59 \mathrm{~cm}$ for the TL detector and the PIN diode). 
In the beginning uncovered TLD's were used in the open-window position. Irregularities in the read-out were related to the presence of ozone $\left(\mathrm{O}_{3}\right)$ in the radioactive gas mixture. This effect disappeared with a $7 \mathrm{mg} / \mathrm{cm}^{2}$ plastic cover. Further investigation of this effect showed that, when exposing ${ }^{7} \mathrm{LiF}$ detectors in air containing $\mathrm{O}_{3}$, new peaks appear in the glow-curve of ${ }^{7} \mathrm{LiF}$. Using a Harshaw model $2000 \mathrm{C}$ TL reader with Glow Curve Analyzer model 2080 we identified a main peak at $\sim 110^{\circ} \mathrm{C}$ and indication of the presence of a peak at $340^{\circ} \mathrm{C}$. An example of an ozone-induced glow curve using the Alnor reader is shown in Fig. 2 for ${ }^{7} \mathrm{LiF}$ exposed during 2 hours at $5 \mathrm{ppm}$. As can be seen, the peak appears after. $\sim 2.5 \mathrm{~s}$ (channel 25), while the principal radiation-induced maximum for LiF appears after $4 \mathrm{~s}$ (channel 40 ) for the same read-out conditions. The growth of the $\mathrm{O}_{3}$-induced signal versus time is shown in Fig. 2 for ${ }^{7} \mathrm{LiF}$ exposed in air containing 2 ppm of $\mathrm{O}_{3}$. The upper curve shows the increase of the net read-out value, while for the lower curve the ratio between 10 channels $(1$ s) in the peak region and the ten last channels of the Alnor glow curve for the ozone-exposed TLD's is compared with the same ratio for unexposed TLD's. Apparently saturation is reached after about 1 hour. A further increase in concentration up to $11 \mathrm{ppm}$ did not significantly increase the read-out value for the 2 hour exposure. Like in the case with light exposure of ${ }^{7}$ LiF 5 ), the ozone is clearly a surface effect and has consequently a wide spread in read-out values. Typical TL response values found after exposure of $0.5 \mathrm{~h}$ in air containing $2 \mathrm{ppm}$ of $\mathrm{O}_{3}$ were equivalent to doses up to $90 \mu \mathrm{Sv}$ of $1^{37} \mathrm{Cs}$ under the readout conditions used (no pre-read anneal!).

\section{CONCLUSION}

From the results prsented in this paper we concluded that to obtain reproducible results for air monitoring it is necessary to irradiate TL detectors in a well-defined volume and, consequently, we constructed test chambers of $30 \mathrm{~cm}$ diameter $x 30 \mathrm{~cm}$, since the dose value does not increase substantially anymore when increasing the height above $30 \mathrm{~cm}$ (see Fig. 1). Such devices can be useful also to monitor air outside beam areas in case radioactivity might be present accidentally. The chamber wall protects the TLD's against external $\beta$ sources so that only air activity inside the chamber is detected. It has been shown in this paper that proper sealing of the $T L$ detectors is necessary to avoid spurious effects caused by the presence of ozone. Silicon PIN photodiodes were found to be useful for air monitoring in target areas. In these areas it will have a considerably longer life expectance than GM counters, while its price is at least lower by a factor of 20 in addition to much simpler and consequently 
cheaper electronics.

\section{ACKNOWLEDGEMENTS}

The authors are grateful to R. Deltenre, G. Roubaud and $C$. Raffnsøe for their help during the experiments.

\section{REFERENCES}

1. Tuyn, J.W.N., Radiation Protection Monitoring around High-Energy Proton Accelerators using Thermoluminescence Dosemeters. Radiat. Prot. Dosim. 2(2) 69-74 (1982).

2. Peetermans, A., Activation de $I^{\prime}$ Air près du synchrocyclotron ISOLDE, CERN Report DI/HP/157 (1972).

3. Peetermans, A., Calibration Expérimentale et Calculée des Chambres d'Ionisation à Circulation d'Air, CERN report 72(112972).

4. Slapa, M. et al., Silicon Pulse Chamber for Measurement of X-and Gamma Dose Rate, Nucl. Instr. and Meth. 96, 239.

5. Tuyn, J.W.N. and Lakshmanan, A.R., Light Sensitivity of Some Common Thermoluminescence Dosimetry Phosphors, Radiat. Prot. Dosim. 5(3) 183-185 (1983).

\section{FIGURE CAPTIONS}

Fig. 1 Dose and count rate versus radioactive air column height for LIF TLD-700 and silicon PIN photodiode, respectively.

Fig. 2 Ozone-induced glow-curve in ${ }^{7}$ LiF TLD-700 measured with an automatic Alnor hot nitrogen reader after $2 \mathrm{~h}$ exposure in air containing 5 ppm of $\mathrm{O}_{3}$.

Fig. 3 Net ozone-induced read-out (upper curve) and ratio between peak ratios measured for $\mathrm{O}_{3}$ exposed and unexposed ${ }^{7} \mathrm{LiF}$ TLD-700 versus exposure time to air containing $2 \mathrm{ppm}$ of $\mathrm{O}_{3}$. 


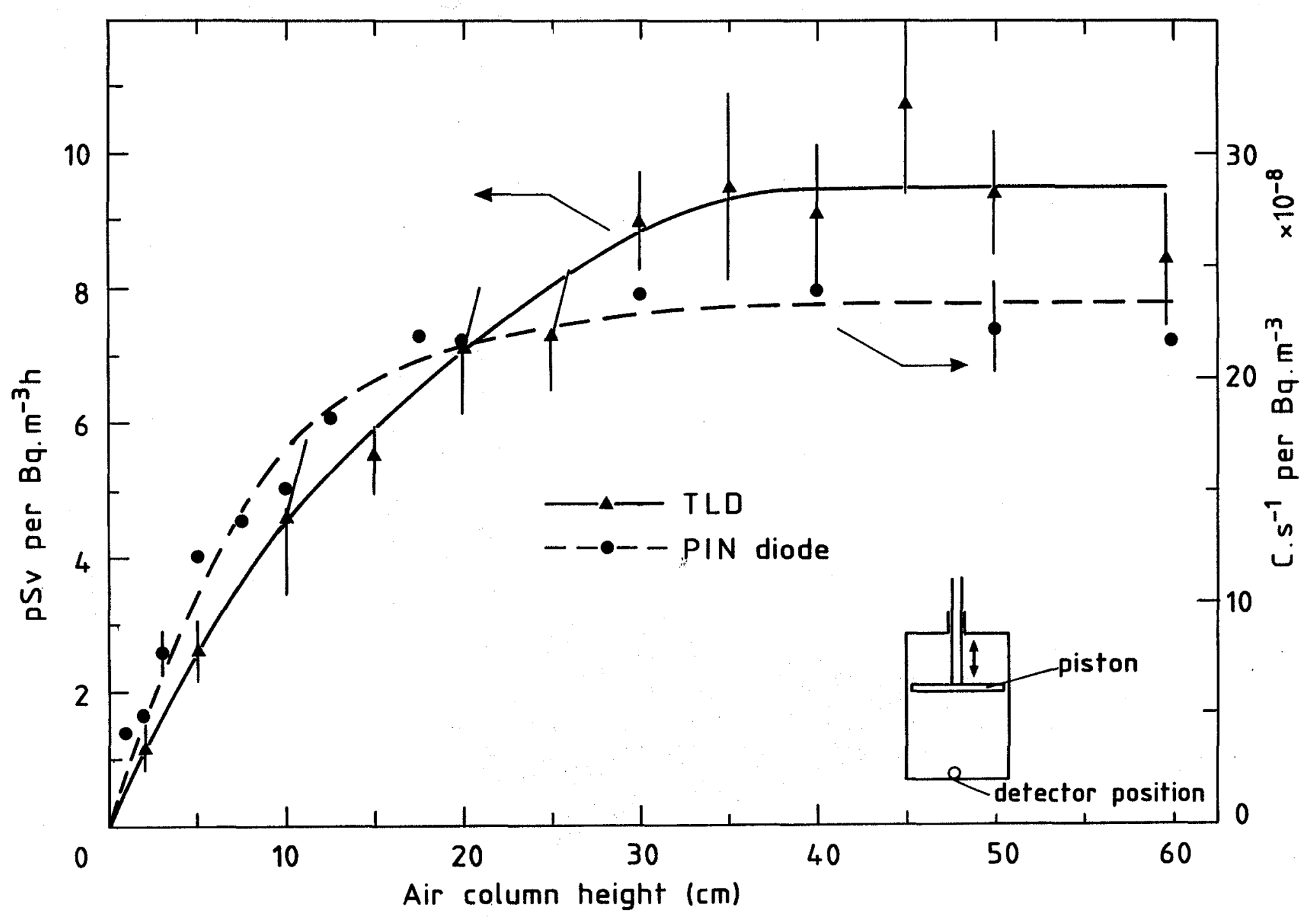

Fig. 1 


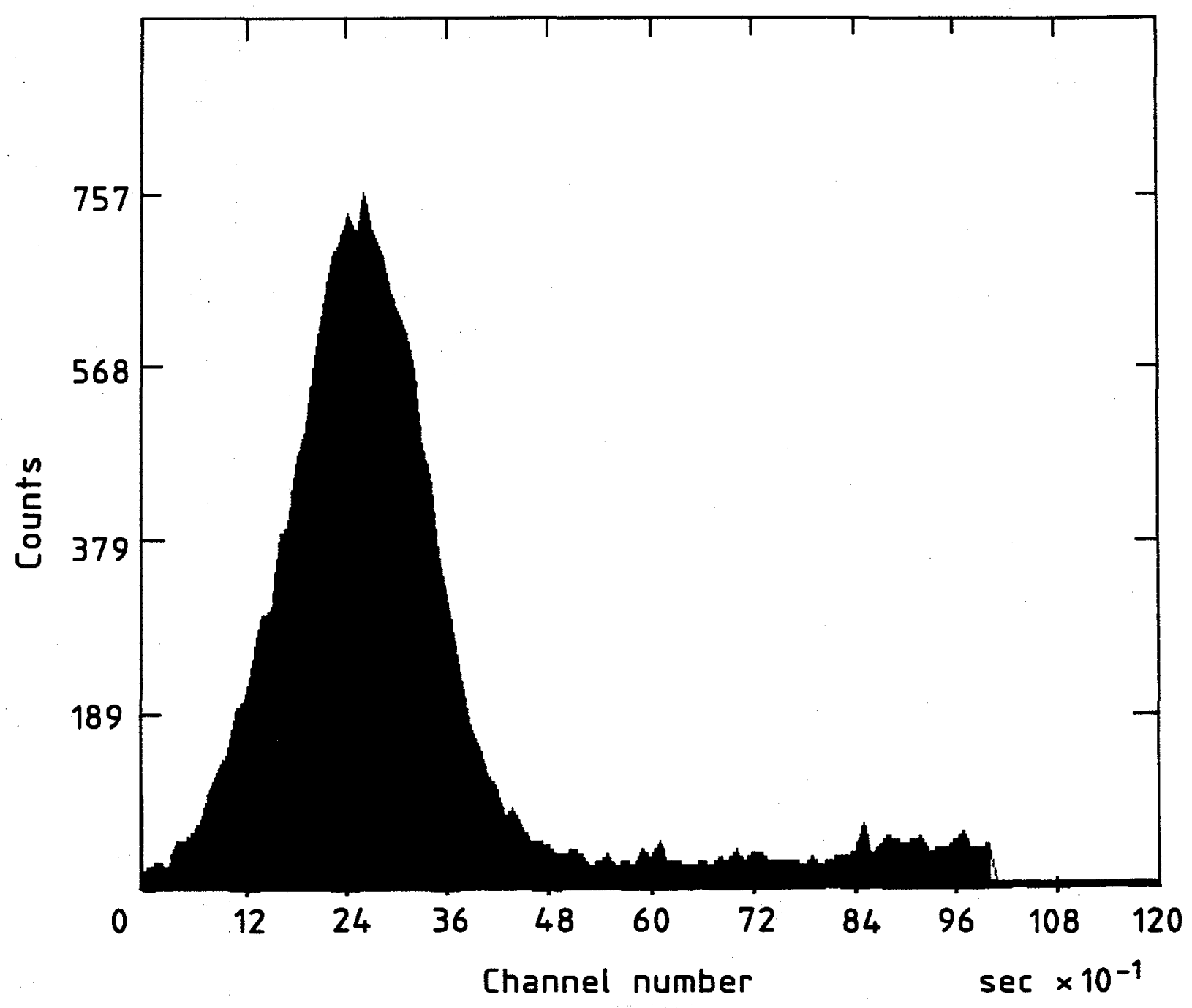

Fig. 2 


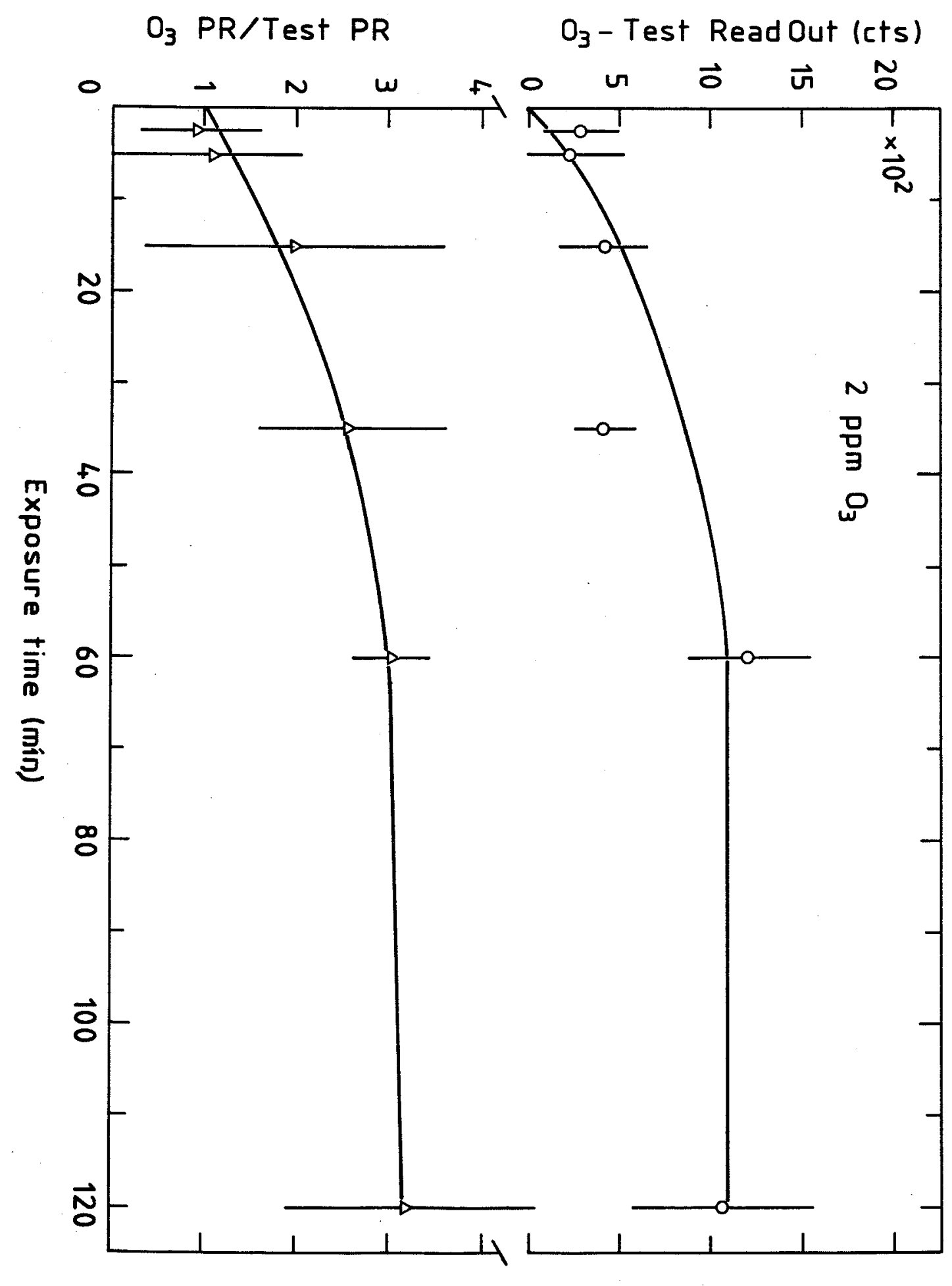

Fig. 3 